\title{
Coordination of Receptor Signaling in Multiple Hematopoietic Cell Lineages by the Adaptor Protein SLP-76
}

\author{
Martha S. Jordan ${ }^{1,2}$ and Gary A. Koretzky ${ }^{1,2,3}$ \\ ${ }^{1}$ Abramson Family Cancer Institute, University of Pennsylvania, Philadelphia, Pennsylvania 19104 \\ ${ }^{2}$ Department of Pathology and Laboratory Medicine, University of Pennsylvania, Philadelphia, Pennsylvania \\ 19104 \\ ${ }^{3}$ Department of Medicine, University of Pennsylvania, Philadelphia, Pennsylvania 19104 \\ Correspondence: koretzky@mail.med.upenn.edu
}

The adaptor protein SLP-76 is expressed in multiple hematopoietic lineages including T cells, platelets, and neutrophils. SLP-76 mediated signaling is dependent on its multiple protein interaction domains, as it creates a scaffold on which key signaling complexes are built. SLP-76 is critical for supporting signaling downstream of both immunoreceptors and integrins. The signaling molecules used both upstream and downstream of SLP-76 are similar among these receptors and across cell types; however, important differences exist. Appreciating how SLP-76 coordinates signal transduction across different cell and receptor types provides insights into the complex interplay of pathways critical for activation of cells of the immune system that are essential for host defense.

\begin{abstract}
daptor proteins are an important compoAnent of many signaling systems both within and beyond the immune system. Unlike enzymes that catalyze the chemical reactions required for signal propagation, adaptor proteins are molecular platforms on which other proteins assemble. Although lacking enzymatic function, adaptor proteins regulate signaling by stabilizing or restricting molecular interactions required for proper enzyme activation and for localizing these key effector molecules appropriately within the cell.
\end{abstract}

Src homology 2 (SH2) domain-containing leukocyte protein of $76 \mathrm{kDa}$ (SLP-76) is an adaptor present in a number of hematopoietic cell lineages including $\mathrm{T}$ cells, platelets, neutrophils, mast cells, macrophages, and NK cells. There are two SLP-76 homologs: SLP-65/B cell linker protein (BLNK), and cytokinedependent hematopoietic cell linker (CLNK), also known as mast cell immunoreceptor signal transducer (MIST). BLNK is expressed in B cells and monocytes, and CLNK is expressed in mast cells, activated T cells, and NK cells. SLP-76 was

Editors: Lawrence E. Samelson and Andrey Shaw

Additional Perspectives on Immunoreceptor Signaling available at www.cshperspectives.org

Copyright (C) 2010 Cold Spring Harbor Laboratory Press; all rights reserved; doi: 10.1101/cshperspect.a002501

Cite this article as Cold Spring Harb Perspect Biol 2010;2:a002501 
first identified in $\mathrm{T}$ cells as a substrate of T-cell receptor (TCR) stimulated protein tyrosine kinases (PTKs) through "pull down" experiments using immobilized growth factor receptorbound protein 2 (Grb2) (Jackman et al. 1995). Since then, SLP-76 has been shown to be critically important in the development of $\mathrm{T}$ cells and for propagating signals downstream of not only the TCR but also additional receptors present on hematopoietic cells.

\section{A MODEL FOR SLP-76 FUNCTION FOLLOWING IMMUNORECEPTOR ENGAGEMENT}

TCR stimulation results in activation of Lck, a member of the Src family of PTKs, leading to phosphorylation of immunoreceptor tyrosinebased activation motifs (ITAMs) present within the CD3 chains of the TCR. Phosphorylated ITAMS recruit the Syk PTK ZAP-70, which is responsible for tyrosine phosphorylation of several proteins including the adaptors linker for activation of T cells (LAT) (Zhang et al. 1998) and SLP-76 (Bubeck Wardenburg et al. 1996). Phosphorylation of these adaptors is a critical step in the assembly of the LAT/SLP-76 signaling complex and is necessary for the recruitment and activation of additional proteins including phospholipase C $\gamma 1$ (PLC $\gamma 1$ ), the phospholipase responsible for hydrolysis of phosphatidylinositol 4,5-bisphosphate (PIP2) and generation of the critical second messengers inositol trisphosphate (IP3) and diacylglycerol (DAG).

Initial insights into the role of SLP-76 in TCR signaling arose from overexpression studies performed in the Jurkat T-cell line, demonstrating that increased expression of SLP-76 led to enhanced TCR signaling. The complementary loss-of-function studies including the generation of SLP-76 deficient Jurkat cells (J14) (Yablonski et al. 1998) and SLP-76 deficient mice (Clements et al. 1998; Pivniouk et al. 1998) revealed the essential role of SLP-76 in T-cell biology. Although TCR stimulation of J14 cells still results in Lck and ZAP-70 activation, TCR ligation fails to result in activation of key signaling components including PLC $\gamma 1$
(Yablonski et al. 1998), resulting in diminished $\mathrm{Ca}^{2+}$ flux, protein kinase C- $\theta$ (PKC $\theta$ ) activation, Erk phosphorylation, and decreased activity of several transcriptional reporter constructs, including nuclear factor of activated $\mathrm{T}$ cells (NFAT) and activator protein-1 (AP-1) (Yablonski et al. 1998; Herndon et al. 2001). In vivo, SLP-76 deficiency results in a complete failure to generate mature $\mathrm{T}$ cells. T-cell development in mice deficient for SLP-76 is blocked at the transition from the $\mathrm{DN} 3\left(\mathrm{CD} 4^{-} \mathrm{CD} 8^{-}\right.$, double negative) to DN4 stage (Clements et al. 1998; Pivniouk et al. 1998), a transition that requires signaling from the pre-TCR. Many of the biochemical defects described in J14 cells have now been shown in $\mathrm{T}$ cells from mice that generate a normal T-cell repertoire before excision of endogenous SLP-76 through crelox technology (Maltzman et al. 2005).

SLP-76 was defined initially as having three functional domains: the amino-terminal acidic domain, the central proline rich region (PPR), and the carboxy-terminal SH2 domain (Fig. 1). The amino terminus contains three tyrosines at amino acids 112 (113 in humans), 128 , and 145 that become phosphorylated after TCR stimulation. When mutated at all three tyrosine residues (Y3F mutant), SLP-76 loses nearly all of its ability to support PLC $\gamma 1$ and PKC $\theta$ activation, $\mathrm{Ca}^{2+}$ flux, and Erk phosphorylation (Musci et al. 1997b; Yablonski et al. 1998; Herndon et al. 2001). Mutation of this domain also leads to the dysregulation of actin polymerization and polarized actin cap formation following TCR stimulation (Bubeck Wardenburg et al. 1998). Loss of these functions has been associated with the inability of the Y3F SLP-76 mutant to associate with Vav1, the adaptor noncatalytic region of tyrosine kinase (Nck), and IL-2-inducible T-cell kinase (Itk), the proteins shown to bind to these phosphorylated tyrosines. In cell lines, mutation of tyrosines 112 and/or 128 abrogates the inducible association of SLP-76 with the guanine nucleotide exchange factor (GEF) Vav1 and Nck, two proteins involved in actin reorganization (Wu et al. 1996; Raab et al. 1997; Bubeck Wardenburg et al. 1998). Mutation of Y145 results in the loss of binding to Itk, a Tec family tyrosine kinase 


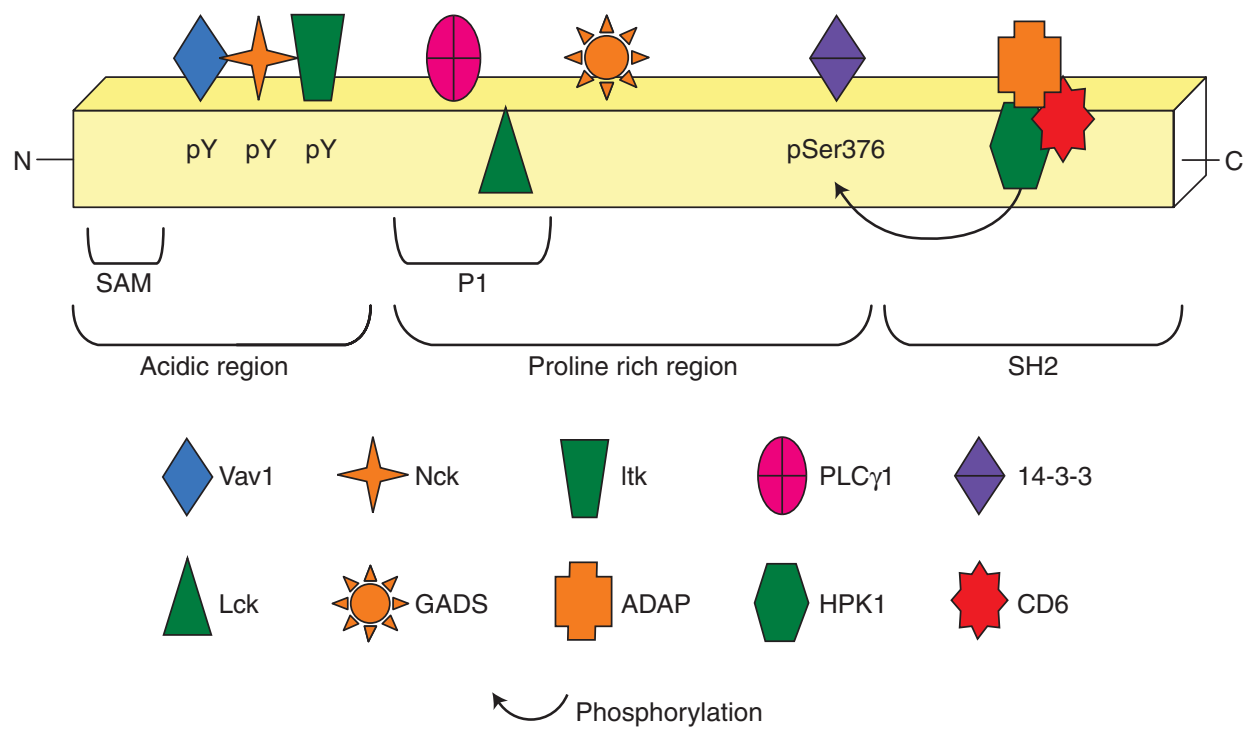

Figure 1. The domains of SLP-76 regulate its function. SLP-76 contains multiple regions that dictate its localization and association with other signaling molecules (adaptors in orange and kinases in green). The amino terminus contains three tyrosines that become phosphorylated after TCR ligation and function together to regulate the activity of Itk and activation of PLC $\gamma 1$. This region also contains a critical SAM domain. The proline-rich region constitutively binds Gads as well as PLC 1 and Lck, which lie within a PRR subdomain termed P1. Serine 376 in the PRR is a target for HPK1 phosphorylation that appears to allow for the subsequent binding of 14-3-3 family members. The carboxyl terminus of SLP-76 harbors an SH2 domain that associates with phosphorylated ADAP, CD6, and HPK1. The interaction of the SH2 domain with HPK1 regulates its kinase activity.

important for PLC $\gamma 1$ activation (Su et al. 1999; Bunnell et al. 2000). Based on these protein/ protein associations, original models posited that loss of Vav1 and Nck binding primarily result in decreased actin reorganization, whereas loss of Itk association leads to defective PLC $\gamma 1$ activation. As discussed later, further investigations have shown that the role of these proteins is more complex than originally described.

To determine the in vivo consequence of mutating these three tyrosines, SLP- $76^{-/-}$ mice were reconstituted with wild-type (WT) or a Y3F mutant SLP-76 (Myung et al. 2001; Kumar et al. 2002). Expression of the Y3F SLP-76 transgene partially relieves the DN3 thymic block, enabling double positive $\left(\mathrm{CD}^{+}\right.$ $\left.\mathrm{CD}^{+}, \mathrm{DP}\right)$ thymocytes to develop; however, progression to the mature single positive $\left(\mathrm{CD} 4^{+} \mathrm{CD} 8^{-}\right.$or $\left.\mathrm{CD}^{-} \mathrm{CD}^{+}, \mathrm{SP}\right)$ stage is dramatically impaired. The $\mathrm{T}$ cells that do arise fail to proliferate or form actin caps in response to TCR stimulation in addition to those biochemical defects observed in Y3F-expressing J14 cells (Myung et al. 2001; Kumar et al. 2002).

The central PRR of SLP-76 contains a novel SH3-domain binding motif (RxxK) that is responsible for the constitutive association of SLP-76 with the carboxy-terminal SH3 domain of the adaptor Gads (Asada et al. 1999; Liu et al. 1999; Berry et al. 2002). Gads also contains an SH2 domain that mediates its interaction with phosphorylated LAT (Asada et al. 1999; Liu et al. 1999). LAT is constitutively located in glycolipid-enriched membrane (GEM) microdomains present within the plasma membrane, and the relocalization of SLP-76 from the cytosol to the GEMs and into the LAT-nucleated complex requires its interaction with Gads (Singer et al. 2004; Bunnell et al. 2006). Disruption of the SLP-76/Gads interaction results in diminished $\mathrm{Ca}^{2+}$ flux, IP3 generation, and activation of Erk, PLC $\gamma 1$, and NFAT (Musci et al. 
1997b; Yablonski et al. 2001; Singer et al. 2004). In vivo, transgenic expression of a Gads-binding mutant allows for DP thymocyte development and progression of some thymocytes to the SP stage, but development is far from normal, as the thymic size is only $20 \%$ of that seen in WT SLP-76 reconstituted mice (Myung et al. 2001; Kumar et al. 2002). The smaller thymic size is at least in part because of the requirement of this region for proper positive selection (Jordan et al. 2007). Peripheral T cells in Gads-binding mutant mice are only weakly activated downstream of the TCR, as shown by their decreased ability to up-regulate activation markers, flux $\mathrm{Ca}^{2+}$, and proliferate (Myung et al. 2001; Kumar et al. 2002). The ability to retain SLP-76 function above that seen in the Y3F mutant and in the face of disrupted SLP-76 localization may be because of retention of SLP-76 phosphorylation under these circumstances (Yablonski et al. 2001).

The third primary region of SLP-76 is its carboxy-terminal SH2 domain, which inducibly associates with adhesion and degranulationpromoting adapter protein (ADAP) and the serine-threonine kinase hematopoietic progenitor kinase 1 (HPK1) (Musci et al. 1997a; Sauer et al. 2001). Early studies in Jurkat cells gave little insight into the function of the $\mathrm{SH} 2$ domain, other than the finding that its absence led to only modest decreases in PLC $\gamma 1$ and Erk activation (Yablonski et al. 2001). Additional studies showed a requirement for this domain in the activation of HPK1, although the cellular consequences of this function are unclear (Liou et al. 2000; Sauer et al. 2001). Transgenic expression of an SH2 SLP-76 mutant on a SLP-76 ${ }^{-1}$ - background allows for the generation of mature $\mathrm{T}$ cells that show nearly normal $\mathrm{Ca}^{2+}$ flux and Erk activation but diminished proliferation (Myung et al. 2001; Kumar et al. 2002). These characteristics are similar to those seen in mice deficient in ADAP, which is known to be required for the up-regulation and activation of integrins (Griffiths et al. 2001; Peterson et al. 2001). Based on these similarities, the primary role of this domain was assumed to be that of supporting of ADAP function in integrin activation.

\section{NEW INSIGHTS INTO HOW THE STRUCTURE OF SLP-76 MEDIATES ITS FUNCTION}

Over the past several years, further investigation into the structure of SLP-76 has led to more sophisticated models of how SLP-76 operates. These studies include analysis of mice expressing double or single mutations in the aminoterminal tyrosines of SLP-76, identification of additional regions within the amino terminus and PPR, and further in vivo analysis of the SH2 domain (Table 1).

The Amino Terminus: SLP-76 Tyrosines and the SAM Domain

To understand how the individual aminoterminal tyrosines of SLP-76 contribute to its function, knockin mice bearing mutations at both tyrosines 112 and 128 or tyrosine 145 alone were generated (Jordan et al. 2008). Unlike Y3F transgenic mice that have a paucity of mature thymocytes, both Y112/128F and Y145F mice produce mature thymocytes and peripheral $\mathrm{T}$ cells, although positive and negative selection is severely defective, as revealed by crossing the tyrosine mutants to mice expressing TCR transgenes. Biochemically, T cells from both SLP-76 mutant strains show impaired but not absent $\mathrm{Ca}^{2+}$ flux, actin polymerization and phosphorylation of PLC $y 1$ and Erk, with Y145F thymocytes consistently demonstrating a more severe phenotype both biochemically and developmentally. The similarity between Y112/128F and Y145F mice clearly demonstrate that there is coordinate regulation of multiple signaling pathways downstream of the amino-terminal tyrosines of SLP-76 in terms of PLC $\gamma 1$ activation as well as actin reorganization.

This in vivo observation of coordinate regulation of actin polymerization and PLC $\gamma 1$ function is largely supported by mechanistic studies performed in cell lines. In Jurkat cells, the amino-terminal tyrosines of SLP-76 are important for the relocalization of Nck and its binding partner WASP, an actin regulatory protein, to the $\mathrm{T}$ cell:APC interface. These tyrosines also 
Table 1. Summary of signaling and developmental defects reported for primary T cells expressing mutant forms of SLP-76.

\begin{tabular}{|c|c|c|c|c|}
\hline Domain & Mutation name & $\begin{array}{l}\text { Defective } \\
\text { signaling }\end{array}$ & Developmental defects & $\begin{array}{c}\text { Defects in peripheral } \\
\text { T-cell function }\end{array}$ \\
\hline \multirow[t]{4}{*}{$\begin{array}{l}\text { Amino } \\
\text { terminus }\end{array}$} & $\Delta$ SAM-SLP-76 ${ }^{1}$ & $\mathrm{Ca}^{2+}$ flux, pErk & $\begin{array}{l}\text { Thymic size, } \mathrm{DP} \rightarrow \mathrm{SP},(+) \text { and } \\
\quad(-) \text { selection }\end{array}$ & $\begin{array}{l}\text { Proliferation, IL-2 } \\
\text { production, SLP-76 } \\
\text { clustering }\end{array}$ \\
\hline & $\mathrm{Y}_{3} \mathrm{~F}^{2}$ & $\begin{array}{l}\text { pSLP-76, } \\
\text { pPLC } \gamma 1, \mathrm{Ca}^{2+} \\
\text { flux }\end{array}$ & $\begin{array}{l}\text { Thymic size, DN3 } \rightarrow \text { DN4, } \\
\quad \mathrm{DP} \rightarrow \mathrm{SP}\end{array}$ & $\begin{array}{l}\text { CD69/CD25 up- } \\
\text { regulation, } \\
\text { proliferation, TCR } \\
\text { clustering }\end{array}$ \\
\hline & $\mathrm{Y} 112 / 128 \mathrm{~F}^{3}$ & $\begin{array}{l}\text { pSLP-76, pVav1, } \\
\text { pPLC } \gamma 1 \\
\mathrm{Ca}^{2+}, \text { pErk, } \\
\text { actin }\end{array}$ & $\begin{array}{l}\mathrm{DP} \rightarrow \mathrm{SP},(+) \text { and }(-) \text { selection, } \\
\quad \text { Nur77 upregulation }\end{array}$ & Not reported \\
\hline & $\mathrm{Y} 145 \mathrm{~F}^{3}$ & $\begin{array}{l}\text { pPLC } \gamma 1, \mathrm{Ca}^{2+} \\
\text { pErk, actin }\end{array}$ & $\begin{array}{c}\mathrm{DP} \rightarrow \mathrm{SP},(+) \text { and }(-) \text { selection, } \\
\text { Nur77 up-regulation, } \uparrow \mathrm{CD} 8 \mathrm{SP} \\
\text { with memory/innate markers }\end{array}$ & Not reported \\
\hline \multirow[t]{3}{*}{ PRR } & $\begin{array}{l}\text { Gads Binding } \\
\text { Mutant }^{2,4}\end{array}$ & pPLC $\gamma 1, \mathrm{Ca}^{2+}$ & $\begin{array}{l}\text { Thymic size, DP } \rightarrow \mathrm{SP},(+) \\
\text { selection }\end{array}$ & $\begin{array}{l}\text { CD69/CD25 } \\
\text { up-regulation, } \\
\text { proliferation, TCR } \\
\text { clustering }\end{array}$ \\
\hline & $\mathrm{P} 1^{5 *}$ & $\begin{array}{l}\text { pPLC } \gamma 1, \mathrm{Ca}^{2+}, \\
\text { pErk }\end{array}$ & n.d. & n.d. \\
\hline & $\mathrm{Lck}^{6}$ & $\begin{array}{l}\text { pPLC } \gamma 1, \mathrm{Ca}^{2+} \\
\text { pErk }\end{array}$ & $\begin{array}{l}\text { Thymic size, DN3 } \rightarrow \text { DN4, } \\
\quad \mathrm{DP} \rightarrow \mathrm{SP}\end{array}$ & $\begin{array}{l}\text { CD25 up-regulation, } \\
\text { proliferation, IL-2 } \\
\text { production }\end{array}$ \\
\hline $\mathrm{SH} 2$ & $\mathrm{R} 448 \mathrm{~K}^{2,7}$ & $\begin{array}{l}\text { pSLP-76 Ser376, } \\
\text { pPKD, }\end{array}$ & $\begin{array}{l}\mathrm{DN} 3 \rightarrow \mathrm{DN} 4, \mathrm{DP} \rightarrow \mathrm{SP},(+) \\
\quad \text { selection }\end{array}$ & $\begin{array}{l}\text { CD69/CD25 } \\
\text { up-regulation, } \\
\text { proliferation, IL-2 } \\
\text { production }\end{array}$ \\
\hline
\end{tabular}

1. Shen et al. 2009 .

2. Myung et al. 2001.

3. Jordan et al. 2008 .

4. Jordan et al. 2007.

${ }^{*}$ Data reported for cell lines.

5. Yablonski et al. 2001.

6. Kumar et al. 2005.

7. M. S. J. unpublished data.

direct the membrane recruitment of Vav1 and activated Cdc42, a GTPase required for WASP activation and a target of Vavl GEF activity (Zeng et al. 2003). Such studies suggested that the coordinated recruitment of Vav1 and Nck and the subsequent activation of their targets or binding partners were sufficient for actin regulation. However, studies in $\mathrm{Itk}^{-/-} \mathrm{T}$ cells revealed that recruitment of activated WASP, Cdc42, and Vav1 to the T cell:APC interface is also dependent on Itk and specifically its SH2 domain, which interacts with Y145 of SLP-76. It was further shown that Itk is important for establishing/stabilizing the interaction between SLP-76 and Vav1 (Labno et al. 2003; Dombroski et al. 2005). These studies support a model in which all three tyrosines of SLP-76 and their respective binding partners function together to properly regulate TCR-induced actin polymerization. 
Similar to actin regulation, cell line studies also support the notion that PLC $\gamma 1$ regulation is controlled by multiple SLP-76 binding partners. Such studies revealed that the aminoterminal tyrosines of SLP-76 are required for Itk kinase activity and that the majority of catalytically active Itk is associated with SLP-76 (Bogin et al. 2007). However, Vav1 also regulates Itk and PLC $\gamma 1$ activation as well as the interaction between SLP-76 and PLC $\gamma 1$ (Reynolds et al. 2002). These data, when considered with the role of Itk in mediating Vav1/SLP-76 interactions, suggest that these molecules must be involved in coordinate regulation of one another and that they function together to support many if not most of the signaling pathways following TCR engagement. In generating a unified model of SLP-76 function using data from primary $\mathrm{T}$ cells and cell lines, it is important to acknowledge that unlike in Jurkat cells where mutation of the amino-terminal tyrosines result in loss of SLP-76 associations with Vav1, Nck, and Itk, introduction of these mutations into primary $\mathrm{T}$ cells does not (Jordan et al. 2008). Thus, it appears that formation of the signaling complex in primary cells results from numerous intermolecular interactions. It remains likely, however, that the SLP-76 tyrosines are still critical for binding to Vav1, Nck, and Itk, and that these associations are essential for optimal function of each of the SLP-76-associated proteins.

Although several similarities exist between Y112/128F and Y145F mutant mice, there are also distinct differences. TCR stimulation of thymocytes from Y112/128F but not Y145F mice fails to result in phosphorylation of Vav1 following TCR stimulation, whereas mutation of Y145 but not Y112/128 results in the selection of CD8SP thymocytes that have characteristics shared by memory and/or innate-like $\mathrm{T}$ cells (Jordan et al. 2008). Two distinct features of these CD8SP cells are their capacity to produce copious amounts of IFN $\gamma$ directly ex vivo and their expression of high levels of eomesodermin, a transcription factor found at elevated levels in memory $\mathrm{CD}^{+} \mathrm{T}$ cells. Because Itk deficiency also leads to increased development of this thymic subset, it is likely that
SLP-76-dependent activation of Itk regulates their development (Atherly et al. 2006; Broussard et al. 2006). How tyrosine 145 of SLP-76 plays a role in the regulation of eomesodermin is unclear, but insight into this question will likely be informative in understanding $\mathrm{T}$ cell fate decisions both in the thymus and in memory T-cell development.

The generation of SLP-76 tyrosine mutant mice led to experiments addressing whether the two mutations could complement one another functionally in vivo when coexpressed. Double-mutant mice (mice expressing one Y112/128F and one Y145F allele) were analyzed for T-cell development and for signaling downstream of the TCR (Jordan et al. 2008). Thymocyte development in double-mutant mice is phenotypically and functionally normal, with no increase in CD8SP memory/innate-like T cells, as seen selectively in Y145F mice. Biochemically, expression of both mutant alleles restores Vav1 phosphorylation, a selective defect seen in Y112/128F thymocytes, and PLC $\gamma 1$ phosphorylation, a defect shared by both lineages. These data demonstrate that downstream of the TCR, active Vav1, Nck, and Itk do not have to be present on the same SLP-76 molecule to support wild-type signal transduction. However, given the plethora of data indicating that these proteins coordinately regulate one another, it is likely that formation of a signaling complex consisting of at least two SLP-76 molecules forms following TCR ligation. Such a complex may be dependent on LAT, which has been shown to oligomerize after TCR stimulation because of its inducible association with Grb2 (Houtman et al. 2006). The precise stoichiometry of the LAT/SLP-76 complex has yet to be defined.

The amino terminus of SLP-76 also contains a sterile- $\alpha$ motif (SAM) located just proximal to tyrosines 112,128 , and 145 at amino acids $12-78$. This motif was identified several years ago, but only recently has its function begun to be appreciated. SAM domains typically mediate protein/protein interactions that may or may not involve other SAM domains. Currently, it is not known what interaction(s) the SAM domain of SLP-76 mediates, 
but knockin mice with a mutation in this motif demonstrate its importance in thymocyte development (Shen et al. 2009). Thymocytes from $\triangle$ SAM-SLP-76 mice transition through the DN stages of development relatively normally, but diminished numbers are present at the DP and SP stages, consistent with defects in both positive and negative selection. Following TCR engagement, $\mathrm{T}$ cells from these mice show decreased $\mathrm{Ca}^{2+}$ flux and Erk activation accompanied by weak clustering of SLP-76. Mechanistically, the underlying cause of these observed defects is not known, but they are at least partially independent of the SLP-76/Gads interaction, as mice bearing mutations in both of these domains show severe developmental defects of thymic subsets (Shen et al. 2009).

\section{The SLP-76 PRR: The P1 Domain and Ser376 Phosphorylation}

In addition to the Gads-binding site, other important regions within the PRR of SLP-76 have recently been described. Defined as a region necessary for the basal association of SLP-76 with PLC 11 , the P1 domain (amino acids 157-223) was shown to be important for activating several pathways downstream of SLP-76, including PLC $\gamma 1$ and Erk phosphorylation, IP3 production, and NFAT activation (Yablonski et al. 2001). Further studies showed that the critical aspect of this region probably lies more in its role as a "molecular spacer" rather than mediating an essential protein/protein interaction (Gonen et al. 2005). However, manipulation of this domain can lead to loss of SLP-76/Vav1 associations and/or SLP-76associated Itk kinase activity, both of which are associated with decreased PLC $\gamma 1$ activation (Beach et al. 2007).

Other residues within the PRR have been identified as either additional regions of protein/protein interaction or sites of phosphorylation. Amino acids 185-194, just proximal to the Gads-binding domain, mediate a constitutive interaction with the SH3 domain of Lck (Sanzenbacher et al. 1999). The importance of this region was recognized through in vivo expression of a SLP-76A185-194 mutant on a SLP- $76^{-/-}$background. Mice bearing this mutation have a severe DN3 block and very few peripheral $\mathrm{T}$ cells that show only residual function (Kumar et al. 2005). Despite these dramatic defects, it is unclear how the loss of Lck binding to SLP-76 leads to this phenotype. It is possible that disruption of SLP-76/Lck prevents proper phosphorylation of Itk by Lck (Heyeck et al. 1997). Recently, serine 376 within the PRR was shown to be phosphorylated by the kinase HPK1, one of the binding partners of the SLP-76 SH2 domain. Phosphorylation at this site results in decreased TCR signal transduction. Although the mechanism has yet to be defined, early studies suggest that 14-3-3 family members, which are recruited to SLP-76 following Ser376 phosphorylation, may play a role (Di Bartolo et al. 2007; Shui et al. 2007).

\section{The SLP-76 SH2 Domain: ADAP Dependent and Independent Functions}

Because of its association with ADAP, the SLP-76 SH2 domain has been implicated in TCRinduced integrin activation. For full activation, integrins must undergo both affinity and avidity changes. These changes are governed by engagement of other cell surface receptors, such as the TCR, that lead to conformational changes in integrins and integrin clustering. These changes increase integrin affinity and avidity, respectively, for ligands and are referred to as "insideout" signaling. Support for a role for SLP-76 in inside-out signaling comes from studies performed in cell lines, which showed that mutation of ADAP at sites of SLP-76/ADAP interaction diminish the ability of $\mathrm{T}$ cells to adhere to integrin-coated surfaces (Wang et al. 2004; Kliche et al. 2006). Until recently, data linking the SLP-76 SH2 domain was based on mutational analysis of ADAP. New data in primary $\mathrm{T}$ cells now reveal that mutation of the SLP-76 SH2 domain itself inhibits TCR-induced inside-out signaling (Baker et al. 2009). These data also reveal a role for this domain in signaling directly downstream of integrin engagement (discussed later).

The molecular mechanism for SLP-76 mediated inside-out signaling to integrins is thus 
likely ADAP dependent. In addition to its inducible interaction with SLP-76, ADAP is constitutively present in a trimolecular complex with Src kinase-associated phosphoprotein of $55 \mathrm{kDa}$ (SKAP55), via a direct interaction, and Ras-proximity-1 (Rap1)-GTP-interacting adapter molecule (RIAM), via a tertiary interaction. On TCR stimulation, this ADAP/RIAM/ SKAP55 complex associates with the small GTPase Rap1 and is responsible for the relocalization of activated Rap1 to the membrane, where it aids in promoting clustering and affinity modulation of integrins, a step necessary for their full activation (Kliche et al. 2006; Menasche et al. 2007). It has been shown that neither ADAP (Kliche et al. 2006) nor the SLP-76 SH2 domain (unpubl. data) regulates Rap1 activation. However, recent data indicate that SLP76 is involved in the activation of this GTPase, although the domain requirements have not been identified (Horn et al. 2009).

Recent in vivo studies comparing the function of primary $\mathrm{T}$ cells harboring a SLP-76 $\mathrm{SH} 2$ domain mutation to ADAP-deficient $\mathrm{T}$ cells suggest that some $\mathrm{SH} 2$ domain functions are ADAP independent. Specifically, PKD phosphorylation, a target of PKC $\theta$, and phosphorylation of SLP-76 on Ser376, an HPK1 target, is dependent on the SLP-76 SH2 domain but not ADAP (M.S.J. unpubl. data). These findings indicate that the pathways downstream of the SLP-76 SH2 domain and ADAP are not linear, and they may help explain why activation of NFKB targets is more defective in the absence of a functional SLP-76 SH2 domain versus in the deficiency of ADAP (M.S.J. unpubl. data).

The full function of the SLP-76 SH2 domain may not be solely based on ADAP and HPK1 interactions. This domain can also associate with the cytoplasmic tail of the T-cell surface receptor CD6 (Hassan et al. 2006). Studies have shown that engagement of CD6 costimulates TCR-driven IL- 2 production and that mutation of the tyrosine on CD6 that mediates its interaction with SLP-76 abolishes CD6 costimulation (Hassan et al. 2006). How this mutation affects in vivo function awaits further investigations.

\section{SLP-76 SIGNALING IN OTHER HEMATOPOIETIC CELLS}

Initial insight into the function of SLP-76 was based solely on its role in TCR signaling. Subsequent evaluation of signal transduction in platelets and neutrophils has shown that SLP76 is important for supporting signals downstream of immunoreceptors present on non- $\mathrm{T}$ cells and provided the first evidence for the role of SLP-76 downstream of integrins. Experiments examining the molecular basis of SLP-76 function in various lineages allow for interesting comparisons between the requirements of signal propagation downstream of a variety of receptor systems.

\section{GPVI and Fc $\gamma R$ Signaling in Platelets and Neutrophils}

Platelets use multiple cell surface receptors to maintain hemostasis, including the collagen receptor GPVI and integrins of the $\beta 1$ and $\beta 2$ families. Acting as a first line of defense, neutrophils rely on FcyRs for recognition of IgGopsonized particles or soluble IgG immune complexes and integrins, including the $\beta 2$ integrin Mac-1 (CD18/CD11b), for adhesion to extracellular matrix proteins. GPVI associates with the Fcy chain and thus propagates signals in a manner similar to that of the Fc $\gamma \mathrm{R}$ present on neutrophils. Like TCR signaling, the Fc $\gamma \mathrm{R}$ cascade relies on phosphorylation of ITAMs present within the Fcy chain by Src family members (Lyn and/or Fyn, Hgr, and Fgr for platelets and neutrophils and Lck for T cells) followed by recruitment of Syk (ZAP-70 in T cells) to these phosphorylated motifs. Activated Syk is required for subsequent phosphorylation of PLC $\gamma 2$, a critical activator of downstream effector functions. Ligation of GPVI in platelets and $\mathrm{Fc} \gamma \mathrm{R}$ in neutrophils results in actin reorganization, cell spreading, degranulation, aggregation in the case of platelets, and production of reactive oxygen intermediates (ROI) in the case of neutrophils. All of these functions are dependent on SLP-76, as platelets and neutrophils from SLP-76-deficient mice either fail completely or show greatly reduced responses 
when these events are interrogated (Clements et al. 1999; Newbrough et al. 2003). Although the molecular mechanism defining how SLP76 contributes to PLC $\gamma$ activation and several other SLP-76-dependent pathways have been best described in T cells, many of the same effector molecules, including Vav and Tec family members, have also been shown to be important for signaling downstream of platelet and neutrophil FcyRs (reviewed in Bezman and Koretzky 2007). Similar to signaling downstream of the TCR, LAT is phosphorylated following GPVI stimulation and is required for optimal platelet degranulation following stimulation with convulxin, a selective GPVI agonist (Gibbins et al. 1998; Judd et al. 2002). In T cells, Gads is largely required for development and peripheral T-cell function; however, in platelets, the role for Gads is more complex. For some GPV1-mediated functions such as convulxininduced degranulation, Gads is completely dispensable (Judd et al. 2002). In contrast, Gads is required for optimal GPVI-induced aggregation (Hughes et al. 2008). Therefore, although signaling through a SLP-76/LAT axis is common between the TCR and GPVI, their differential requirement for Gads in certain functions indicates that downstream integration of signals for these receptors can be distinct.

Integrin Signaling in Platelets and Neutrophils

Signaling downstream of integrins is also dependent on SLP-76 and has been described best in platelets and neutrophils (Fig. 2). Similar to the TCR, engagement of Fc $\gamma$ Rs can induce the integrin affinity and avidity changes required for full integrin activation.

Once activated, ligation of integrins such as $\alpha$ IIb $\beta$ IIIa on platelets and Mac-1 on neutrophils by fibrinogen or polyRGD (an engineered tri-peptide integrin binding motif) results in "outside-in" signaling from the integrin. Similar to the TCR and FcyR, integrin outside-in signaling uses Src and Syk protein tyrosine kinases as well as SLP-76 and many of its associated molecules for signal propagation. Exactly how integrins, which lack ITAMs, couple to Syk is an area of active investigation. Coupling may be through a direct ITAM-independent interaction (Woodside et al. 2001) or may rely on associations with ITAM-bearing receptors, such as the Fcy chain or DAP12, as suggested from recent studies performed in mice deficient in these ITAM-bearing proteins (Mocsai et al. 2006). Under normal circumstances, integrin ligation results in cell spreading, ROI production, and degranulation of intracellular components; however, these functions are greatly impaired in platelets and/or neutrophils lacking SLP-76 (Judd et al. 2000; Judd et al. 2002; Newbrough et al. 2003). The decreased functions observed in vitro correlate with altered neutrophil and platelet-dependent functions in vivo, as mice lacking SLP-76 within the myeloid compartment show defective integrindependent accumulation and degranulation of neutrophils as measured by a model of LPSinduced dermal inflammation (Clemens et al. 2007). Moreover, mice bearing particular SLP76 mutations within their platelets fail to form stable thrombi in a model of arterial thrombosis (Bezman et al. 2008). These data demonstrate the importance of SLP-76 in these non-T-cell compartments.

\section{Structure/Function Studies of SLP-76 in Platelets and Neutrophils}

Mice reconstituted with bone marrow progenitor cells from SLP-76-deficient mice expressing mutant forms of SLP-76 have been critically important in determining the domain requirements of SLP-76 in non-T-cell immunoreceptor and integrin function. Using this system, it was shown, similar to their essential role in TCR signal transduction, that the amino-terminal tyrosines of SLP-76 are critical for downstream propagation of GPVI as well as integrin initiated signaling (Abtahian et al. 2006). Y3F-expressing platelets fail to degranulate in response to GPVI, and diminished platelet spreading and neutrophil ROI production is observed in Y3F-expressing cells stimulated through their integrin receptors. Studies in individual aminoterminal tyrosine knockin mice revealed that $\alpha I I b \beta I I I a$ signaling, as measured by platelet spreading, is diminished in mice harboring 
M.S. Jordan and G.A. Koretzky

A SLP-76 mediated signaling downstream of the TCR

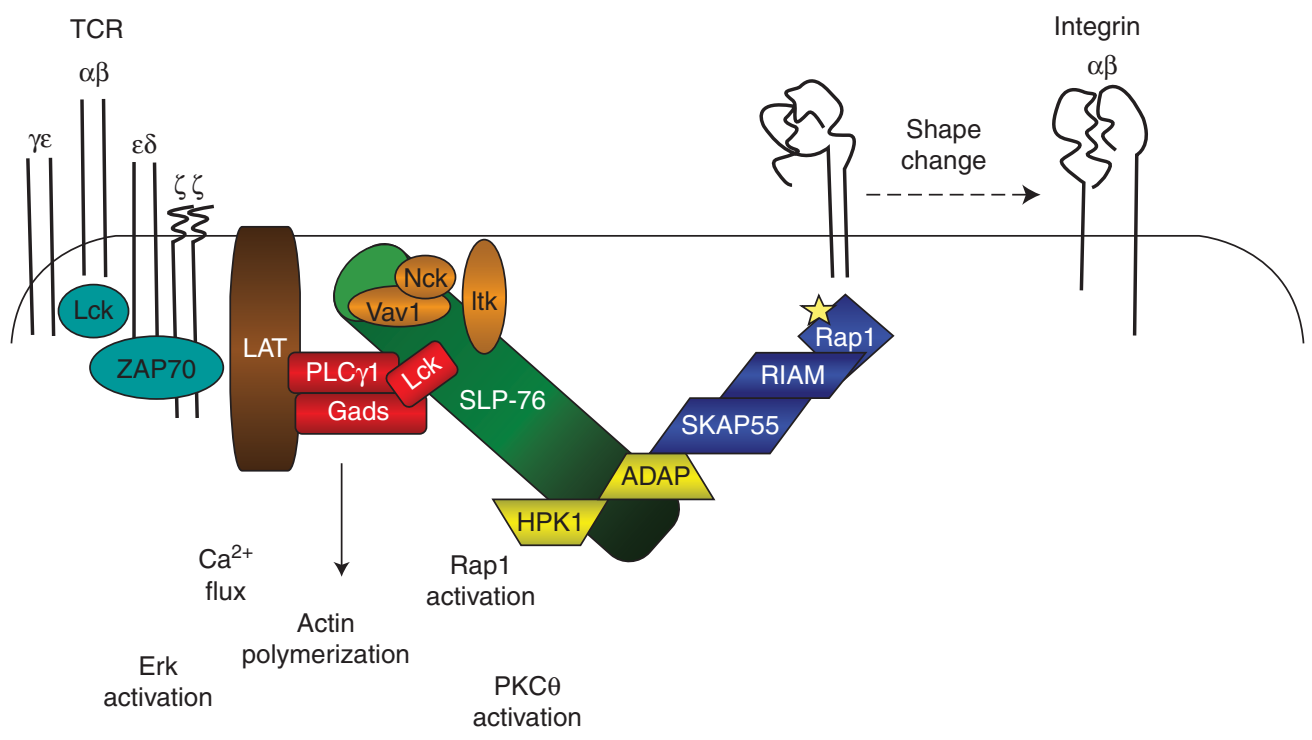

B Outside-in signaling in neutrophils

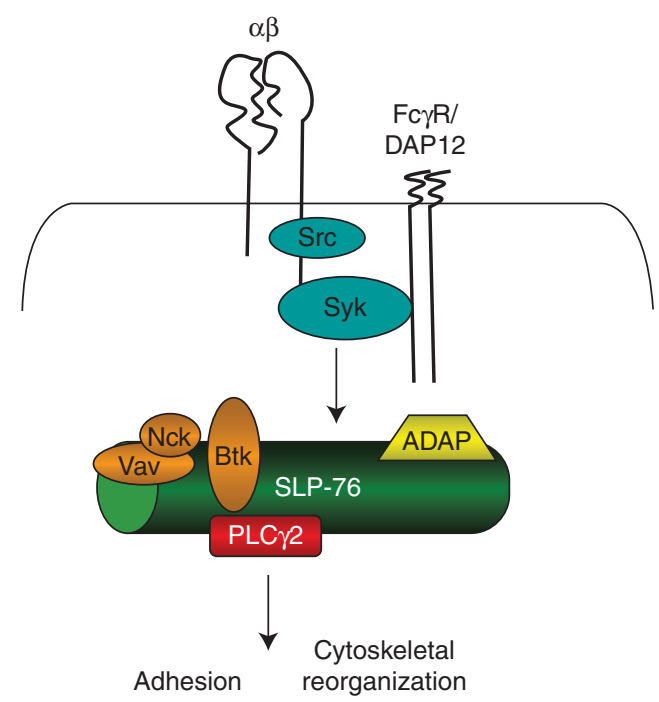

Figure 2. SLP-76 supported TCR and integrin signaling. (A) SLP-76 mediated signaling downstream of the TCR. TCR ligation initiates activation of Lck that phosphorylates ITAMs present on the CD3 chains of the TCR. ZAP-70 is recruited, activated, and phosphorylates LAT and SLP-76. Phosphorylated LAT associates with PLC $\gamma 1$ and Gads and in doing so, recruits SLP-76 to the membrane. Phosphorylated SLP-76 associates with Vav1, Nck, and Itk, which together activate PLC $\gamma 1$ and initiate $\mathrm{Ca}^{2+}$ flux and actin polymerization. SLP-76 also regulates the activation of Erk, PKC $\theta$, and Rap1. Association of SLP-76 with the ADAP/SKAP55/RIAM complex promotes inside-out signaling by localizing active Rap1. Conformational changes mediated by inside-out signaling enable high affinity binding of integrins to their receptors. $(B)$ Outside-in signaling in neutrophils. Integrin ligation activates associated Src kinases in neutrophils. Syk may be recruited to an integrin-associated ITAM-bearing receptor or may directly associate with the integrin $\beta$ chain tail. Activated Syk phosphorylates SLP-76 and initiates PLC 22 activation, leading to cytoskeletal reorganization and cellular adhesion in a LAT- and Gads-independent manner. 
mutations in tyrosines 112 and 128 of SLP-76, whereas platelet spreading in Y145F mutant mice is normal (Bezman et al. 2008). In contrast, GPVI signaling is strikingly more dependent on tyrosine 145 than on tyrosines 112 and 128 for most functions except cell spreading, where both mutants show similar defects. This latter observation of defective Y112/128F spreading may reflect a role for integrin outside-in signaling, which follows GPVI inside-out signaling. It is interesting to note that Vav phosphorylation is defective in Y145F platelets and preserved in Y112/128F platelets, the opposite of what is observed in $\mathrm{T}$ cells bearing these mutations (Jordan et al. 2008). Therefore, although signals transduced downstream of different receptors may use identical or similar proteins, the exact details of how transduction pathways are integrated appear to differ between cell types and receptor classes.

Another intriguing difference between the requirements for the amino-terminal tyrosines of SLP-76 in T cells versus platelets was revealed through complementation experiments. As noted earlier, mice expressing one Y145F and one Y112/128F allele functionally complement one another in trans in $\mathrm{T}$ cells (Jordan et al. 2008). This is not the case for GPVI signaling, as dual expression of each mutant allele results in a functional response that is only marginally better than the response from Y145F platelets (Bezman et al. 2008). Similar results are seen in neutrophils from these mice. Both Y145F and Y112/128F neutrophils display defective Fc $\gamma \mathrm{R}$ and integrin signal transduction, and coexpression of each mutant allele does little to rescue these defects (Lenox et al. 2009). One clue as to why complementation occurs in $\mathrm{T}$ cells and not platelets and neutrophils may lie in the differential requirement for Gads in signaling downstream of the TCR versus GPVI. LAT oligomerizes following TCR ligation (Houtman et al. 2006). Thus, the association of SLP-76 with LAT via Gads may allow for transactivation of those molecules associated with SLP-76 due to their ability to be in close proximity to one another. The fact that Gads is not required for all GPVI functions suggests that the association of SLP-76 with LAT can be regulated differently in T cells versus platelets. It is possible that this difference somehow precludes complementation. Additionally, whether LAT oligomerizes in platelets and whether SLP-76 is affected by this oligomerization remain to be determined. A related possibility that has been posited to explain the discrepancy in complementation is the difference in the number of ITAMs present in the TCR versus the GPVI/FcyR signaling complex (Bezman et al. 2008). The TCR/CD3 complex consists of ten ITAMs compared with the two associated with the Fcy chain. An increased number of ITAMs may result in the assembly of a larger molecular signaling complex, allowing for greater opportunity for transcomplementation.

Analysis of the role of the PRR region of SLP-76 in non-T cells has also revealed differences in the requirements of this domain for downstream signal transduction of various receptors, specifically integrins versus GPVI/ Fc $\gamma$ Rs. In $\mathrm{T}$ cells, mutation of the residues of the PRR that mediate the interaction of SLP-76 with Gads results in greatly diminished but not absent TCR-mediated functions. GPVI signaling in platelets is also dependent on the SLP-76/ Gads interaction domain, although Gads itself can be dispensable under some circumstances, as discussed above (Hughes et al. 2008). In contrast, studies on platelets and neutrophils from chimeric mice expressing mutations in the Gads-binding site have shown that integrin function appears normal in the absence of a SLP-76/Gads interaction, as the mutant platelets spread normally on integrin ligand-coated surfaces and mutant neutrophils produce copious amounts of ROI following integrin stimulation (Abtahian et al. 2006). How SLP-76 functions when it is unable to bind to Gads is unknown. It has been suggested that either SLP-76 does not need to relocalize to the membrane after integrin stimulation or that SLP-76 utilizes other protein interactions to achieve proper localization (Abtahian et al. 2006). Recent studies of integrin outside-in signaling in $\mathrm{T}$ cells have begun to help answer some of these questions.

The integrin studies performed in platelets and neutrophils have paved the way for 
subsequent studies in T cells. Interestingly, however, findings in $\mathrm{T}$ cells may also provide new insights to foster our understanding of integrin signaling in myeloid derived lineages. Similar to what is seen following TCR stimulation, integrin stimulation of $\mathrm{T}$ cells leads to the formation of SLP-76 microclusters that localize with phosphorylated signaling proteins such as ZAP-70 and Lck (Nguyen et al. 2008; Baker et al. 2009). Unlike TCR stimulation, integrin-induced SLP76 clustering does not require LAT or the Gads-binding region of SLP-76 (Baker et al. 2009). These results are consistent with the requirements of SLP-76 domains for integrin activation in platelets and extend our understanding, indicating that SLP-76 clustering downstream of integrins is mediated by proteins other than Gads or by domains outside of the Gads-binding region.

Additional studies investigating the role of the SLP-76 SH2 domain in integrin-mediated signals show that this domain is required for both integrin-induced SLP-76 clustering and outside-in mediated integrin adhesion. Studies in ADAP-deficient $\mathrm{T}$ cells reveal that ADAP is required for these same functions, suggesting that perhaps ADAP plays a role in SLP76 membrane localization following integrin stimulation. Interestingly, ADAP is not required for SLP-76 clustering post-TCR ligation (Baker et al. 2009). Whether these findings are applicable to platelets and neutrophils remains to be determined, but these data do provide yet another example of differential regulation of SLP-76 and the signaling pathways it supports.

\section{ADDITIONAL ROLES OF SLP-76}

In this article, we discussed only a subset of cell types and receptor systems in which SLP-76 plays a role. In addition to the lineages considered above, mast cells use SLP-76 to transduce signals downstream of FceRI. SLP-76-deficient mast cells have impaired cytokine release, degranulation, and $\mathrm{Ca}^{2+}$ flux, and these mice are resistant to IgE-induced passive systemic anaphylaxis (Pivniouk et al. 1999). Structure/function analysis has revealed that the functional hierarchy of the domains of SLP-76 in mast cells is similar to that seen in T cells (Wu et al. 2004). Very recently, mice deficient in SLP-76 were also shown to be resistant to serum-induced arthritis, a disease that is dependent on functional mast cells and neutrophils, which highlights the in vivo importance of SLP-76 in these lineages (Lenox et al. 2009).

SLP-76 also impacts systems beyond hematopoietic cells. The subcutaneous hemorrhaging observed in most SLP-76-deficient fetuses and the blood-filled peritoneum seen in surviving pups was initially attributed to defective platelet function. However, this phenotype was shown subsequently to be the result of improper vascular development with a failure of blood and lymphatic vessels to separate normally (Abtahian et al. 2003). The exact means by which SLP-76 controls this separation has yet to be determined.

In the years since the identification and initial characterization of SLP-76 as a substrate of TCR-stimulated PTKs, much has been learned about the details of how this protein functions, both in T cells and other immune lineages. It is likely that this key adaptor protein has yet other roles, perhaps as a regulator of signals initiated by additional cell surface receptors. Insights gleaned from studies of how SLP-76 regulates immune cell development and function have provided important information about the complexities of signaling in these lineages, and they have also taught us a great deal about more general principles of how signal transduction cascades are integrated by adaptor proteins. We anticipate that future studies of SLP-76, using mice in which expression of mutant variants of this protein can be more tightly regulated temporally and in a lineage specific manner, will teach us much more about the intricate processes of cell differentiation and fate decisions and more globally about how the immune system uses various strategies for optimal host defense.

\section{ACKNOWLEDGMENTS}

We thank Justina Stadanlick for excellent editorial assistance. 


\section{REFERENCES}

Abtahian F, Bezman N, Clemens R, Sebzda E, Cheng L, Shattil SJ, Kahn ML, Koretzky GA. 2006. Evidence for the requirement of ITAM domains but not SLP-76/Gads interaction for integrin signaling in hematopoietic cells. Mol Cell Biol 26: 6936-6949.

Abtahian F, Guerriero A, Sebzda E, Lu MM, Zhou R, Mocsai A, Myers EE, Huang B, Jackson DG, Ferrari VA, et al. 2003. Regulation of blood and lymphatic vascular separation by signaling proteins SLP-76 and Syk. Science 299: 247-251.

Asada H, Ishii N, Sasaki Y, Endo K, Kasai H, Tanaka N, Takeshita T, Tsuchiya S, Konno T, Sugamura K. 1999. Grf40, A novel Grb2 family member is involved in T cell signaling through interaction with SLP-76 and LAT. J Exp Med 189: $1383-1390$.

Atherly LO, Lucas JA, Felices M, Yin CC, Reiner SL, Berg LJ. 2006. The Tec family tyrosine kinases Itk and Rlk regulate the development of conventional CD8 + T cells. Immunity 25: 79-91.

Baker RG, Hsu CJ, Lee D, Jordan MS, Maltzman JS, Hammer DA, Baumgart T, Koretzky GA. 2009. The adapter protein SLP-76 mediates "outside-in" integrin signaling and function in T cells. Mol Cell Biol doi: 10.1128/ MCB.00283-09.

Beach D, Gonen R, Bogin Y, Reischl IG, Yablonski D. 2007. Dual role of SLP-76 in mediating T cell receptor-induced activation of phospholipase C-gamma1. J Biol Chem 282: 2937-2946.

Berry DM, Nash P, Liu SK, Pawson T, McGlade CJ. 2002. A high-affinity Arg-X-X-Lys SH3 binding motif confers specificity for the interaction between Gads and SLP-76 in T cell signaling. Curr Biol 12: 1336-1341.

Bezman N, Koretzky GA. 2007. Compartmentalization of ITAM and integrin signaling by adapter molecules. Immunol Rev 218: 9-28.

Bezman NA, Lian L, Abrams CS, Brass LF, Kahn ML, Jordan MS, Koretzky GA. 2008. Requirements of SLP76 tyrosines in ITAM and integrin receptor signaling and in platelet function in vivo. J Exp Med 205: 1775-1788.

Bogin Y, Ainey C, Beach D, Yablonski D. 2007. SLP-76 mediates and maintains activation of the Tec family kinase ITK via the T cell antigen receptor-induced association between SLP-76 and ITK. Proc Natl Acad Sci 104: 6638-6643.

Broussard C, Fleischacker C, Horai R, Chetana M, Venegas AM, Sharp LL, Hedrick SM, Fowlkes BJ, Schwartzberg PL. 2006. Altered development of CD8 + T cell lineages in mice deficient for the Tec kinases Itk and Rlk. Immunity 25: 93-104.

Bubeck Wardenburg J, Fu C, Jackman JK, Flotow H, Wilkinson SE, Williams DH, Johnson R, Kong G, Chan AC, Findell PR. 1996. Phosphorylation of SLP-76 by the ZAP-70 protein-tyrosine kinase is required for T-cell receptor function. J Biol Chem 271: 19641-19644.

Bubeck Wardenburg J, Pappu R, Bu JY, Mayer B, Chernoff J, Straus D, Chan AC. 1998. Regulation of PAK activation and the $\mathrm{T}$ cell cytoskeleton by the linker protein SLP-76. Immunity 9: 607-616.

Bunnell SC, Diehn M, Yaffe MB, Findell PR, Cantley LC, Berg LJ. 2000. Biochemical interactions integrating Itk
Regulation of Signaling by the Adaptor SLP-76

with the $\mathrm{T}$ cell receptor-initiated signaling cascade. J Biol Chem 275: 2219-2230.

Bunnell SC, Singer AL, Hong DI, Jacque BH, Jordan MS, Seminario MC, Barr VA, Koretzky GA, Samelson LE. 2006. Persistence of cooperatively stabilized signaling clusters drives T-cell activation. Mol Cell Biol 26: 7155 7166.

Clemens RA, Lenox LE, Kambayashi T, Bezman N, Maltzman JS, Nichols KE, Koretzky GA. 2007. Loss of SLP-76 expression within myeloid cells confers resistance to neutrophil-mediated tissue damage while maintaining effective bacterial killing. J Immunol 178: 4606-4614.

Clements JL, Lee JR, Gross B, Yang B, Olson JD, Sandra A, Watson SP, Lentz SR, Koretzky GA. 1999. Fetal hemorrhage and platelet dysfunction in SLP-76-deficient mice. The Journal of clinical investigation 103: 19-25.

Clements JL, Yang B, Ross-Barta SE, Eliason SL, Hrstka RF, Williamson RA, Koretzky GA. 1998. Requirement for the leukocyte-specific adapter protein SLP-76 for normal T cell development. Science 281: 416-419.

Di Bartolo V, Montagne B, Salek M, Jungwirth B, Carrette F, Fourtane J, Sol-Foulon N, Michel F, Schwartz O, Lehmann WD, et al. 2007. A novel pathway downmodulating $\mathrm{T}$ cell activation involves HPK-1-dependent recruitment of 14-3-3 proteins on SLP-76. J Exp Med 204: 681-691.

Dombroski D, Houghtling RA, Labno CM, Precht P, Takesono A, Caplen NJ, Billadeau DD, Wange RL, Burkhardt JK, Schwartzberg PL. 2005. Kinase-independent functions for Itk in TCR-induced regulation of Vav and the actin cytoskeleton. J Immunol 174: 1385-1392.

Gibbins JM, Briddon S, Shutes A, van Vugt MJ, van de Winkel JG, Saito T, Watson SP. 1998. The p85 subunit of phosphatidylinositol 3-kinase associates with the $\mathrm{Fc}$ receptor gamma-chain and linker for activitor of T cells (LAT) in platelets stimulated by collagen and convulxin. J Biol Chem 273: 34437-34443.

Gonen R, Beach D, Ainey C, Yablonski D. 2005. T cell receptor-induced activation of phospholipase $\mathrm{C}$-gammal depends on a sequence-independent function of the P-I region of SLP-76. J Biol Chem 280: 8364-8370.

Griffiths EK, Krawczyk C, Kong YY, Raab M, Hyduk SJ, Bouchard D, Chan VS, Kozieradzki I, Oliveira-Dos-Santos AJ, Wakeham A, et al. 2001. Positive regulation of T cell activation and integrin adhesion by the adapter Fyb/ Slap. Science 293: 2260-2263.

Hassan NJ, Simmonds SJ, Clarkson NG, Hanrahan S, Puklavec MJ, Bomb M, Barclay AN, Brown MH. 2006. CD6 regulates T-cell responses through activation-dependent recruitment of the positive regulator SLP-76. Mol Cell Biol 26: 6727-6738.

Herndon TM, Shan XC, Tsokos GC, Wange RL. 2001. ZAP-70 and SLP-76 regulate protein kinase C-theta and NF-kappa B activation in response to engagement of CD3 and CD28. J Immunol 166: 5654-5664.

Heyeck SD, Wilcox HM, Bunnell SC, Berg LJ. 1997. Lck phosphorylates the activation loop tyrosine of the Itk kinase domain and activates Itk kinase activity. J Biol Chem 272: 25401-25408.

Horn J, Wang X, Reichardt P, Stradal TE, Warnecke N, Simeoni L, Gunzer M, Yablonski D, Schraven B, Kliche S. 2009. Src homology 2-domain containing 
M.S. Jordan and G.A. Koretzky

leukocyte-specific phosphoprotein of $76 \mathrm{kDa}$ Is mandatory for TCR-mediated inside-out signaling, but dispensable for CXCR4-mediated LFA-1 activation, adhesion, and migration of T cells. J Immunol 183: 5756-5767.

Houtman JC, Yamaguchi H, Barda-Saad M, Braiman A, Bowden B, Appella E, Schuck P, Samelson LE. 2006. Oligomerization of signaling complexes by the multipoint binding of GRB2 to both LAT and SOS1. Nat Structural Mol Biol 13: 798-805.

Hughes CE, Auger JM, McGlade J, Eble JA, Pearce AC, Watson SP. 2008. Differential roles for the adapters Gads and LAT in platelet activation by GPVI and CLEC-2. J Thromb Haemost 6: 2152-2159.

Jackman JK, Motto DG, Sun Q, Tanemoto M, Turck CW Peltz GA, Koretzky GA, Findell PR. 1995. Molecular cloning of SLP-76, a 76-kDa tyrosine phosphoprotein associated with Grb2 in T cells. J Biol Chem 270: 7029-7032.

Jordan MS, Maltzman JS, Kliche S, Shabason J, Smith JE, Obstfeld A, Schraven B, Koretzky GA. 2007. In vivo disruption of $\mathrm{T}$ cell development by expression of a dominant-negative polypeptide designed to abolish the SLP-76/Gads interaction. Eur J Immunol 37: 2961-2972.

Jordan MS, Smith JE, Burns JC, Austin JE, Nichols KE Aschenbrenner AC, Koretzky GA. 2008. Complementation in trans of altered thymocyte development in mice expressing mutant forms of the adaptor molecule SLP76. Immunity 28: 359-369.

Judd BA, Myung PS, Leng L, Obergfell A, Pear WS, Shattil SJ, Koretzky GA. 2000. Hematopoietic reconstitution of SLP-76 corrects hemostasis and platelet signaling through alpha IIb beta 3 and collagen receptors. Proceedings of the National Academy of Sciences of the United States of America 97: 12056-12061.

Judd BA, Myung PS, Obergfell A, Myers EE, Cheng AM, Watson SP, Pear WS, Allman D, Shattil SJ, Koretzky GA. 2002. Differential requirement for LAT and SLP-76 in GPVI versus T cell receptor signaling. J Exp Med 195: 705-717.

Kliche S, Breitling D, Togni M, Pusch R, Heuer K, Wang X, Freund C, Kasirer-Friede A, Menasche G, Koretzky GA, et al. 2006. The ADAP/SKAP55 signaling module regulates T-cell receptor-mediated integrin activation through plasma membrane targeting of Rap1. Mol Cell Biol 26: 7130-7144.

Kumar L, Feske S, Rao A, Geha RS. 2005. A 10-aa-long sequence in SLP-76 upstream of the Gads binding site is essential for T cell development and function. Proc Natl Acad Sci 102: 19063-19068.

Kumar L, Pivniouk V, de la Fuente MA, Laouini D, Geha RS. 2002. Differential role of SLP-76 domains in T cell development and function. Proc Natl Acad Sci 99: 884-889.

Labno CM, Lewis CM, You D, Leung DW, Takesono A, Kamberos N, Seth A, Finkelstein LD, Rosen MK, Schwartzberg PL, et al. 2003. Itk functions to control actin polymerization at the immune synapse through localized activation of Cdc42 and WASP. Curr Biol 13: 1619-1624.

Lenox LE, Kambayashi T, Okumura M, Prieto C, Sauer K, Bunte RM, Jordan MS, Koretzky GA, Nichols KE. 2009. Mutation of tyrosine 145 of lymphocyte cytosolic protein 2 protects mice from anaphylaxis and arthritis. J Allergy Clin Immunol 124: 1088-1098.
Liou J, Kiefer F, Dang A, Hashimoto A, Cobb MH, Kurosaki T, Weiss A. 2000. HPK1 is activated by lymphocyte antigen receptors and negatively regulates AP-1. Immunity 12: $399-408$.

Liu SK, Fang N, Koretzky GA, McGlade CJ. 1999. The hematopoietic-specific adaptor protein gads functions in T-cell signaling via interactions with the SLP-76 and LAT adaptors. Curr Biol 9: 67-75.

Maltzman JS, Kovoor L, Clements JL, Koretzky GA. 2005. Conditional deletion reveals a cell-autonomous requirement of SLP-76 for thymocyte selection. J Exp Med 202: $893-900$.

Menasche G, Kliche S, Chen EJ, Stradal TE, Schraven B, Koretzky G. 2007. RIAM links the ADAP/SKAP-55 signaling module to Rap1, facilitating T-cell-receptor-mediated integrin activation. Mol Cell Biol 27: 4070-4081.

Mocsai A, Abram CL, Jakus Z, Hu Y, Lanier LL, Lowell CA. 2006. Integrin signaling in neutrophils and macrophages uses adaptors containing immunoreceptor tyrosinebased activation motifs. Nat Immunol 7: 1326-1333.

Musci MA, Hendricks-Taylor LR, Motto DG, Paskind M, Kamens J, Turck CW, Koretzky GA. 1997a. Molecular cloning of SLAP-130, an SLP-76-associated substrate of the $\mathrm{T}$ cell antigen receptor-stimulated protein tyrosine kinases. J Biol Chem 272: 11674-11677.

Musci MA, Motto DG, Ross SE, Fang N, Koretzky GA. 1997b. Three domains of SLP-76 are required for its optimal function in a T cell line. J Immunol 159: 1639-1647.

Myung PS, Derimanov GS, Jordan MS, Punt JA, Liu QH, Judd BA, Meyers EE, Sigmund CD, Freedman BD, Koretzky GA. 2001. Differential requirement for SLP-76 domains in $\mathrm{T}$ cell development and function. Immunity 15: 1011-1026.

Newbrough SA, Mocsai A, Clemens RA, Wu JN, Silverman MA, Singer AL, Lowell CA, Koretzky GA. 2003. SLP-76 regulates Fcgamma receptor and integrin signaling in neutrophils. Immunity 19: 761-769.

Nguyen K, Sylvain NR, Bunnell SC 2008. T cell costimulation via the integrin VLA-4 inhibits the actin-dependent centralization of signaling microclusters containing the adaptor SLP-76. Immunity 28: 810-821.

Peterson EJ, Woods ML, Dmowski SA, Derimanov G, Jordan MS, Wu JN, Myung PS, Liu QH, Pribila JT, Freedman BD, et al. 2001. Coupling of the TCR to integrin activation by Slap-130/Fyb. Science 293: 2263-2265.

Pivniouk V, Tsitsikov E, Swinton P, Rathbun G, Alt FW, Geha RS. 1998. Impaired viability and profound block in thymocyte development in mice lacking the adaptor protein SLP-76. Cell 94: 229-238.

Pivniouk VI, Martin TR, Lu-Kuo JM, Katz HR, Oettgen HC, Geha RS. 1999. SLP-76 deficiency impairs signaling via the high-affinity IgE receptor in mast cells. J Clin Invest 103: $1737-1743$.

Raab M, da Silva AJ, Findell PR, Rudd CE. 1997. Regulation of Vav-SLP-76 binding by ZAP-70 and its relevance to TCR zeta/CD3 induction of interleukin-2. Immunity 6 : 155-164.

Reynolds LF, Smyth LA, Norton T, Freshney N, Downward J, Kioussis D, Tybulewicz VL. 2002. Vav1 transduces T cell receptor signals to the activation of phospholipase 
C-gammal via phosphoinositide 3-kinase-dependent and -independent pathways. J Exp Med 195: 1103-1114.

Sanzenbacher R, Kabelitz D, Janssen O. 1999. SLP-76 binding to p56lck: a role for SLP-76 in CD4-induced desensitization of the TCR/CD3 signaling complex. J Immunol 163: $3143-3152$.

Sauer K, Liou J, Singh SB, Yablonski D, Weiss A, Perlmutter RM. 2001. Hematopoietic progenitor kinase 1 associates physically and functionally with the adaptor proteins $\mathrm{B}$ cell linker protein and SLP-76 in lymphocytes. J Biol Chem 276: 45207-45216.

Shen S, Lau J, Zhu M, Zou J, Fuller D, Li QJ, Zhang W. 2009. The importance of Src homology 2 domain-containing leukocyte phosphoprotein of 76 kilodaltons sterile-alpha motif domain in thymic selection and T-cell activation. Blood 114: 74-84.

Shui JW, Boomer JS, Han J, Xu J, Dement GA, Zhou G, Tan TH. 2007. Hematopoietic progenitor kinase 1 negatively regulates $\mathrm{T}$ cell receptor signaling and $\mathrm{T}$ cell-mediated immune responses. Nat Immunol 8: 84-91.

Singer AL, Bunnell SC, Obstfeld AE, Jordan MS, Wu JN, Myung PS, Samelson LE, Koretzky GA. 2004. Roles of the proline-rich domain in SLP-76 subcellular localization and T cell function. J Biol Chem 279: 15481-15490.

Su YW, Zhang Y, Schweikert J, Koretzky GA, Reth M, Wienands J. 1999. Interaction of SLP adaptors with the $\mathrm{SH} 2$ domain of Tec family kinases. Eur J Immunol 29: 3702-3711.

Wang H, McCann FE, Gordan JD, Wu X, Raab M, Malik TH, Davis DM, Rudd CE. 2004. ADAP-SLP-76 binding differentially regulates supramolecular activation cluster (SMAC) formation relative to T cell-APC conjugation. The Journal of experimental medicine 200: 1063-1074
Regulation of Signaling by the Adaptor SLP-76

Woodside DG, Obergfell A, Leng L, Wilsbacher JL, Miranti CK, Brugge JS, Shattil SJ, Ginsberg MH. 2001. Activation of Syk protein tyrosine kinase through interaction with integrin beta cytoplasmic domains. Curr Biol 11: 1799-1804.

Wu J, Motto DG, Koretzky GA, Weiss A. 1996. Vav and SLP-76 interact and functionally cooperate in IL-2 gene activation. Immunity 4: 593-602.

Wu JN, Jordan MS, Silverman MA, Peterson EJ, Koretzky GA 2004. Differential requirement for adapter proteins Src homology 2 domain-containing leukocyte phosphoprotein of $76 \mathrm{kDa}$ and adhesion- and degranulationpromoting adapter protein in FcepsilonRI signaling and mast cell function. J Immunol 172: 6768-6774.

Yablonski D, Kadlecek T, Weiss A. 2001. Identification of a phospholipase C-gammal (PLC-gamma1) SH3 domainbinding site in SLP-76 required for T-cell receptormediated activation of PLC-gammal and NFAT. Molecular and cellular biology 21: 4208-4218.

Yablonski D, Kuhne MR, Kadlecek T, Weiss A. 1998. Uncoupling of nonreceptor tyrosine kinases from PLC-gammal in an SLP-76-deficient T cell. Science (New York, NY) 281: 413-416.

Zeng R, Cannon JL, Abraham RT, Way M, Billadeau DD, Bubeck-Wardenberg J, Burkhardt JK. 2003. SLP-76 coordinates Nck-dependent Wiskott-Aldrich syndrome protein recruitment with Vav-1/Cdc42-dependent Wiskott-Aldrich syndrome protein activation at the $\mathrm{T}$ cell-APC contact site. J Immunol 171: 1360-1368.

Zhang W, Sloan-Lancaster J, Kitchen J, Trible RP, Samelson LE. 1998. LAT: the ZAP-70 tyrosine kinase substrate that links T cell receptor to cellular activation. Cell 92: 83-92. 


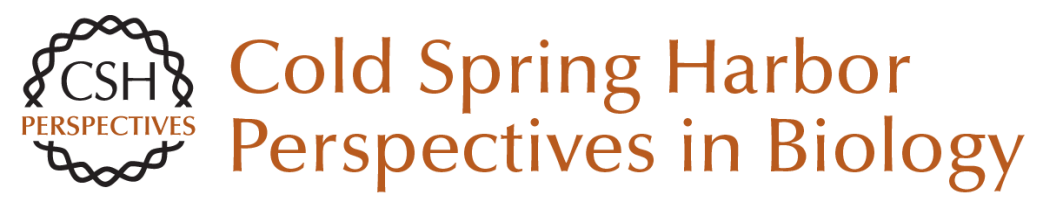

\title{
Coordination of Receptor Signaling in Multiple Hematopoietic Cell Lineages by the Adaptor Protein SLP-76
}

\author{
Martha S. Jordan and Gary A. Koretzky
}

Cold Spring Harb Perspect Biol 2010; doi: 10.1101/cshperspect.a002501 originally published online March 17, 2010

\section{Subject Collection Immunoreceptor Signaling}

The Coordination of T-cell Function by

Serine/Threonine Kinases

David Finlay and Doreen Cantrell

ITAM-mediated Signaling by the T-Cell Antigen Receptor

Paul E. Love and Sandra M. Hayes

Coordination of Receptor Signaling in Multiple Hematopoietic Cell Lineages by the Adaptor

Protein SLP-76

Martha S. Jordan and Gary A. Koretzky

The Cytoskeleton Coordinates the Early Events of B-cell Activation

Naomi E. Harwood and Facundo D. Batista

An Enigmatic Tail of CD28 Signaling

Jonathan S. Boomer and Jonathan M. Green

Mediation of T-Cell Activation by Actin Meshworks

Peter Beemiller and Matthew F. Krummel
Perspectives for Computer Modeling in the Study

of T Cell Activation Jesse Coward, Ronald N. Germain and Grégoire Altan-Bonnet

Structural Biology of the T-cell Receptor: Insights into Receptor Assembly, Ligand Recognition, and Initiation of Signaling

Kai W. Wucherpfennig, Etienne Gagnon, Melissa J. Call, et al.

Src-family and Syk Kinases in Activating and Inhibitory Pathways in Innate Immune Cells:

Signaling Cross Talk Clifford A. Lowell

The LAT Story: A Tale of Cooperativity,

Coordination, and Choreography Lakshmi Balagopalan, Nathan P. Coussens, Eilon Sherman, et al.

Antigen Receptor Signaling to NF- $\mathrm{KB}$ via

CARMA1, BCL10, and MALT1 Margot Thome, Jean Enno Charton, Christiane Pelzer, et al.

It's All About Change: The Antigen-driven Initiation of B-Cell Receptor Signaling Wanli Liu, Hae Won Sohn, Pavel Tolar, et al.

For additional articles in this collection, see http://cshperspectives.cshlp.org/cgi/collection/

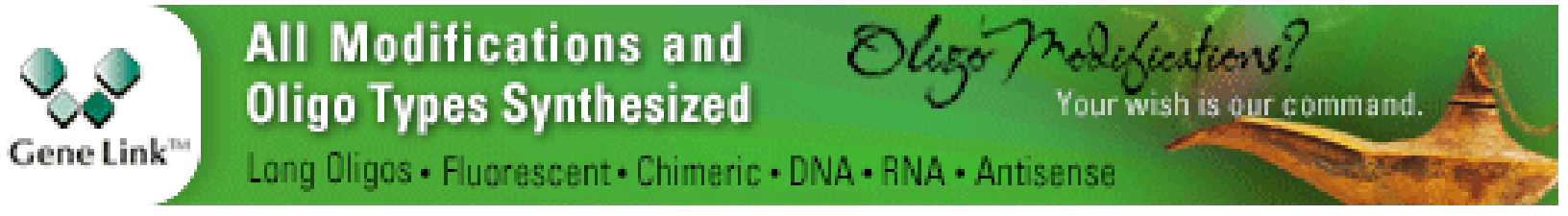


T-Cell Signaling Regulated by the Tec Family

Kinase, Itk

Amy H. Andreotti, Pamela L. Schwartzberg, Raji E. Joseph, et al.

Lipid Signaling in T-Cell Development and

Function

Yina H. Huang and Karsten Sauer
ZAP-70: An Essential Kinase in T-cell Signaling Haopeng Wang, Theresa A. Kadlecek, Byron B. Au-Yeung, et al.

Understanding the Structure and Function of the Immunological Synapse

Michael L. Dustin, Arup K. Chakraborty and Andrey S. Shaw

For additional articles in this collection, see http://cshperspectives.cshlp.org/cgi/collection/

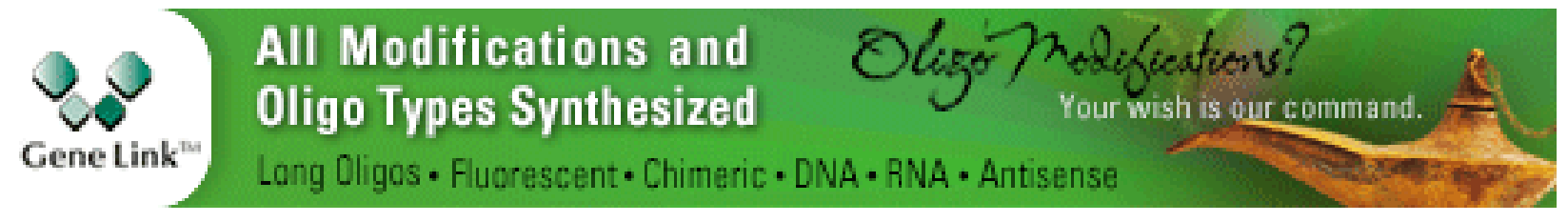

Copyright @ 2010 Cold Spring Harbor Laboratory Press; all rights reserved 